\title{
Investigating Factors Affecting the U.S. National Nursery Trade: The Implications of a Gravity Model
}

\author{
Xiaofang Guo ${ }^{1}$ \\ Department of Applied Economics, University of Minnesota-Twin Cities, St. \\ Paul, MN 55108
}

Chengyan Yue ${ }^{2,4}$

Department of Horticultural Science and Department of Applied Economics, University of Minnesota-Twin Cities, 1970 Folwell Avenue, St. Paul, MN 55108

\author{
Charles R. Hall ${ }^{3}$ \\ Department of Horticultural Science, Texas A\&M University, College Station, \\ TX 77843
}

Additional index words. business characteristics, distance, firm size, gravity model

\begin{abstract}
Literature on the domestic trade of nursery crops is sparse. Based on national survey data collected in years 1999, 2004, and 2009, we used augmented gravity models to investigate the primary factors affecting the value of trade for both large and small nurseries. We found that the impact of distance on trade value was different between large nurseries and small nurseries; the impact of distance on national nursery trade has been decreasing over time; and the level of impact of distance on nursery trade differs across regions. Additionally, the value of nursery trade was affected by plant types the nurseries produced and other business characteristics.
\end{abstract}

In the United States, nursery and greenhouse production represents one of the largest horticulture industry sectors and has become an important contributor to the nation's agricultural economy. The Economic Research Service of the U.S. Department of Agriculture (2007) reports that, in 2006, U.S. nursery and greenhouse crops generated $\$ 16.9$ billion in sales, which was an increase of nearly $18 \%$ since 2000 . Nursery crops include woody ornamental crops such as trees and shrubs including deciduous shade and flowering trees, vines and groundcovers, and foliage plants. According to the latest survey conducted by the National Agricultural Statistics Service, growers of nursery crops in the 17 U.S. states surveyed gained $\$ 4.65$ billion in gross wholesale value in 2006 , which was a $17 \%$ increase from 2003.

\footnotetext{
Received for publication 22 Feb. 2011. Accepted for publication 10 May 2011 .

${ }^{1}$ M.S. graduate student, Department of Applied Economics, University of Minnesota, 1970 Folwell Avenue, St. Paul, MN 55108.

${ }^{2}$ Assistant Professor, Departments of Horticultural Science and Applied Economics, Bachman Endowed Chair in Horticultural Marketing, University of Minnesota, 1970 Folwell Avenue, St. Paul, MN 55108 .

${ }^{3}$ Professor, Department of Horticultural Sciences, Texas A \& M University, 202 Horticulture Forest Science Building, College Station, TX 778432133.

${ }^{4}$ To whom reprint requests should be addressed; e-mail yuechy@umn.edu
}

Another survey that is conducted independently of these government statistics is entitled: Trade Flows and Marketing Practices Within the United States Nursery Industry. The survey has been conducted by the Green Industry Research Consortium five times at 5 -year intervals since 1989 . Several studies have been conducted using the database from these surveys. Hinson et al. (1995) used the 1989 survey data to study choices of nursery transaction channels. Behe et al. (2008) and Hodges et al. (2008) investigated the regional differences in the production and marketing practices in the U.S. nursery industry. Velástegui Andrade and Hinson (2009) subsequently studied choices of nursery market channels.

Few studies have been conducted that investigate the factors that affect the flow of products in nursery crop trade. The gravity model has been widely used for agricultural trade-related studies. Zahniser et al. (2002) explored the impact of regionalism on U.S. agricultural exports using a gravity model. Grant and Lambert (2008) investigated the effects of regional trade agreements on members' agricultural trade. Both studies found that the gravity model performed well on estimating agricultural trade. Koo et al. (1994) used the gravity model for a single agricultural commodity. They found that distances had a significant effect on trade flows of meat. As another type of agricultural product, we hypothesize that factors such as distance and state gross domestic product would also affect the trade of nursery crops. As the name implies, the idea of the gravity model actually stems from Newton's law for gravitational force between two objects. The gravitational force is inversely proportional to the distance between two objects and directly proportional to the masses of objects. In the basic gravity model of trade, the trade flow corresponds to the gravitational force; and the market sizes, which are often measured by gross domestic product (GDP), income, or population, are used to measure masses. Trade flows are expected to be inversely proportional to the distance between two regions and directly proportional to the market sizes. Anderson (1979) developed theoretical justifications for the gravity model. He stated that the gravity model was developed on the basis of constant elasticity of substitution. He assumed that preferences for traded goods are identical across countries and are homothetic and goods are considered differentiated by place of origin. Recently, Deardorff (1998) extended the assumption to all goods. For our study, we assumed preferences for nursery plants are identical across states and nursery plants are differentiated by state of origin.

The gravity model can be augmented with other variables that are related to trade flows. When Tinbergen (1962) first introduced the gravity model to predict international trade flows, the key variables in the model included distance, a measure of market size for both exporting and importing countries, dummy variables for trade agreements, and a dummy variable as a common border in the gravity model. Pöyhönen (1963) used the square root of GDP to represent market size in the gravity model. Population and per-capita income were used by other researchers to measure market size (Carrillo and Li, 2002; Koo and Karamera, 1991; Linnemann, 1966). An augmented gravity model not only includes variables that measure distances and market sizes, but also other variables such as exchange rates, income differences, and dummy variables for infrastructure, common language, or adjacency (Bougheas et al., 1999; Deardorff, 1998; Inmaculanda and Felicitas, 2003).

One of the most important factors that affect trade flows is the actual distance between two regions. A distance variable is used to capture the influence of transportation costs (both freight cost and time cost), which is one of the important parts of trade cost (Anderson and van Wincoop, 2004). Generally, trade increases as transportation cost decreases. Baier and Bergstrand (2001) showed that $\approx 8 \%$ to $9 \%$ of the trade flow growth could be explained by transportation cost reduction. The distance between two regions is often measured by air routes (Frankel, 1997) or by sea routes (Bikker, 1987). Most empirical studies show that distance between two regions negatively affects the trade (Egger, 2002; Leamer and Levinsohn, 1995). The distance between two regions does not change over time. However, transportation costs often change over time. The impact of distance on trade is expected to diminish in magnitude over time because of developments in transportation and storage technology. Several studies have confirmed this hypothesis 
(Bikker, 1987; Brun et al., 2005; Frankel, 1997). A measure of market size is another factor included in gravity models. Generally, variables such as GDP, population, or income are used to measure the market size. Studies have shown that market size affects trade in a positive way: the larger the market size, the larger the trade volume (Llano et al., 2010).

Most nurseries have both intraregional trade and interregional trade with the vast majority of nursery crops produced in the United States being sold to the domestic market. Brooker et al. (2005) reported that less than $10 \%$ of U.S. nurseries exported to foreign countries with those exports representing less than $2 \%$ of total annual firm sales in 2003. As a result of the lack of exports of nursery crops, we focus on the domestic nursery trade within the United States for this study. Previous studies showed that interregional trade tends to grow faster than intraregional and international trade (Hitomi et al., 2000; Munroe and Hewings, 1998). Interregional trade has been studied through various methodologies to estimate the effect of distance, transportation connectivity, and industry characteristics on commodity flows. Gravity models, Neuronal networks, and input-output models are among the well-known methods (Hitomi et al., 2000; Llano et al., 2010, Nijkamp et al., 2004). Llano et al. (2010) used the gravity model to study Spanish interregional trade. More importantly, they showed that the gravity model was a valid method to study interregional trade. Their gravity model estimation indicated that a $1 \%$ increase in the distance between two regions could cause a $1 \%$ decrease in the total bilateral trade in Spain. Similar to Llano et al. (2010), we used the gravity model to explore the major factors affecting domestic interstate nursery trade.

Nursery trade flows are influenced by firm size. Velástegui Andrade and Hinson (2009) explored the impact of business characteristics on market channel by firm size. Their study showed that firm size affected the channel choice and differences exist between large and small nurseries. We expect factors that affect trade flow would differ between large nurseries. Therefore, we model large nurseries and small nurseries separately. To our knowledge, this is the first study to use the gravity model methodology to examine the U.S. domestic nursery trade. In addition, we extended the traditional gravity model specification with augmented variables associated with selected business characteristics. The following business characteristics are included: nursery location, years in business, contracted sales, market channel, percentage of sales to repeat customers, negotiated sales, and the level of exports. All of the major product types aforementioned were also included in the model. Another objective is to explore whether these variables affect the domestic trade conducted by large and small nurseries in different manners. Specifically, we tested the following hypotheses: 1) the impact of distance on large nurseries is smaller than it is on small nurseries; 2) the impact of distance on trade declines over time; 3 ) market sizes of the states where both buyers and sellers are located have positive impacts on the domestic nursery trade; and 4) other business characteristics affect the domestic nursery trade.

\section{Material and Methods}

Data. We used pooled cross-sectional survey data from 3 years to explore how distance, market size, and business characteristics affect the domestic trade in the nursery industry. The data used in this study were collected in 1999, 2004, and 2009 through mail-in surveys or Internet surveys. Twentytwo states participated in the survey in 1999 and 1718 nurseries (24\% response rate) responded to the survey. Forty-four states participated in the survey in 2004 and 2485 nurseries (15.9\% response rate) responded to the survey. In 2009, the survey was sent to nurseries in all 50 U.S. states and 3044 nurseries (18\% response rate) completed the survey (Hall et al., 2011).

We dropped selected observations from the data set if: 1) the destination was out of the United States because our focus was on the domestic nursery trade; 2) gross sales were equal to or less than $\$ 10,000$, based on the USDA definition for commercial production (Velástegui Andrade and Hinson, 2009); 3) information about the year in which the firm was established was missing; 4) information about the nursery's home state was missing; or 5) the percentage breakdown among plant categories was missing. After imposing these conditions, the number of firms in the sample was trimmed to 5140 . The survey asked nursery producers to list the top five or six states (including their own state) that were destinations for their sales and indicate the percentage of sales to each of the five or six destination states. We used the sales to each destination as the dependent variable. Although many nurseries did not provide all five (or six) destinations, the total number of observations was 12,543 .

Model. The impact of distance and business characteristics on trade flow was estimated separately for small nurseries and large nurseries with nursery size measured by each nursery's respective annual gross sales. Survey participants were asked to either write down their actual sales or choose from 11 sales ranges. For the observations that selected the sales ranges, the midpoints of each category were used to approximate the gross sales. Following Velástegui Andrade and Hinson (2009), we used $\$ 500,000$ as the cutoff value to separate large and small nurseries, which resulted in 5,666 observations for large nurseries and 6,877 observations for small nurseries.

Augmented gravity models were used to estimate how different factors affect the domestic trade of nursery crops. The augmented gravity model can be express as follows:

$$
\begin{aligned}
\ln X_{i j}= & \beta_{0}+\beta_{1} \ln Y_{i}+\beta_{2} \ln Y_{j}+\beta_{3} \ln D_{i j} \\
& +\beta_{4} \cdot \mathrm{t} \ln D_{i j}+\beta_{5} \cdot \mathrm{R} \ln D_{i j} \\
& +\beta_{6} \cdot \mathrm{W}+\mu_{i j}
\end{aligned}
$$

where $\mathrm{X}_{\mathrm{ij}}$ is the nursery trade value from state $i$ to state $j ; Y_{i}$ and $Y_{j}$ represent the market sizes of states $\mathrm{i}$ and $\mathrm{j}$, respectively, usually evaluated by the state GDP; $D_{i j}$ is the distance between the two states; $t$ is a vector of the time dummy variable; $R$ is a vector of the region dummy variable; and $W$ is a vector of the dummy variables used to capture the nurseries characteristics. Table 1 presents the description and summary statistics of variables included in the gravity model. $\mu$ is the error term that follows a standard normal distribution. Ordinary least square (OLS) was used to estimate the gravity model. We selected variables in the model based on some model selection criterion such as Akaike's Information Criterion (AIC) and Bayesian's Information Criterion (BIC). $R^{2}$ were used to measure how well the model fits the data. We tested whether the distance and market size significantly affect the trade flow of nursery crops. We also tested whether the impact of distance changes over time and across different regions.

The trade value between two states was reported as a percentage of firms' gross sales and was converted to dollars of sales by multiplying the percentage with the firms' gross sales. The real (adjusted for inflation) GDP by state was used in our study (U.S. Bureau of Economic Analysis, 2010). We defined the distance between the state where the buyer is located (hereafter referred to as the "home state") and the state where the seller is located (hereafter referred to as the "destination state") as the physical distance in miles between the capitals of the two states. We used SAS command zipcitydistance to estimate the distance between the two states. For the case in which the home state was the same as the destination state, we use the radius of the state to approximate the distance.

The interaction terms of the time dummy variable and distance were used in the model to estimate how the impact of distance on trade changes over time. The time dummy variable y2008 (y2003) was defined as one when the trade data were from 2008 (2003); it was zero otherwise. The regions where the sellers are located may have a potential impact on trade value. We classified the regions as Northeast, Midwest, South, and West, similar to the U.S. Census region classification. Interaction terms between distance and the regional dummy variables were also included in the model to explore differences caused by the impact of distance on trade across different regions.

Plant type was also expected to affect the trade value. The data set reported 16 kinds of plants and following Velástegui Andrade and Hinson (2009), we grouped these 16 kinds of plants into five categories based on the product characteristics: trees/shrubs, bedding plants, vines/groundcovers, foliage, and all other. The plant type that accounted for the highest percentage of sales was treated as the major plant type. When two or more plant types had equal percentages of sales and all had the highest percentages, we set all of them as the major plant types.

\section{Results and Discussion}

Average sales by large nurseries were $\approx 15$ times that of small nurseries. Compared with 
Table 1. Description and summary statistics for variables included in the gravity model used to analyze interregional nursery crop trade among U.S. states using combined data from three national surveys.

\begin{tabular}{|c|c|c|c|c|c|c|}
\hline Variable & Description & \multicolumn{2}{|c|}{$\begin{array}{l}\text { Small nurseries } \\
(\mathrm{n}=6877)\end{array}$} & \multicolumn{2}{|c|}{$\begin{array}{l}\text { Large nurseries } \\
\qquad(\mathrm{n}=5666)\end{array}$} & $\begin{array}{c}T \text {-test } \\
P \\
\end{array}$ \\
\hline Trade value & Dollar value of sales to destination state $(\$ 1000)$ & 83.13 & 93.05 & 990.55 & $2,823.73$ & 0.00 \\
\hline Dgdp & Log of destination state GDP (millions of chained 2000 dollars) & 357,530 & 319,059 & 360,968 & 316,360 & 0.55 \\
\hline Y2008 & Dummy variable -1 , if the survey is conducted in 2009 & 0.35 & 0.48 & 0.31 & 0.46 & 0.00 \\
\hline Y2003 & Dummy variable -1 , if the survey is conducted in 2004 & 0.36 & 0.48 & 0.37 & 0.48 & 0.21 \\
\hline Midwest & $\begin{array}{l}\text { Dummy variable-1, if firm in } \\
\text { IL, IN, IA, MI, MN, MO, NE, ND, OH, SD }\end{array}$ & 0.15 & 0.36 & 0.11 & 0.32 & 0.00 \\
\hline West & $\begin{array}{l}\text { Dummy variable-1, if firm in } \\
\text { CA, CO, HI, ID, MT, NV, OR, UT, WA, WY }\end{array}$ & 0.14 & 0.35 & 0.16 & 0.36 & 0.11 \\
\hline Age & Year the survey conducted subtract year the firm established & 22.09 & 17.84 & 33.60 & 23.40 & 0.00 \\
\hline Dold & Dummy variables - 1 , if age is more than 27 years old & 0.25 & 0.43 & 0.49 & 0.50 & 0.00 \\
\hline Wholesale & Dummy variable - 1 , if percentage of wholesale is more than $50 \%$ & 0.60 & 0.49 & 0.87 & 0.34 & 0.00 \\
\hline Repeat & $\begin{array}{l}\text { Dummy variable-1, if percentage of sales to } \\
\text { repeat consumer is more than } 50 \%\end{array}$ & 0.78 & 0.41 & 0.94 & 0.25 & 0.00 \\
\hline Trees/shrubs & Dummy variables - 1 , if the plant group is the major product. & 0.56 & 0.50 & 0.57 & 0.49 & 0.13 \\
\hline Vines/groundcovers & & 0.09 & 0.29 & 0.08 & 0.27 & 0.00 \\
\hline Bedding plants & & 0.14 & 0.35 & 0.13 & 0.33 & 0.02 \\
\hline Foliage & & 0.04 & 0.20 & 0.08 & 0.27 & 0.00 \\
\hline
\end{tabular}

GDP $=$ gross domestic product.

small nurseries, large nurseries have a larger average distance between the home state and destination state, indicating that large nurseries sold their products farther away from the home state relative to small nurseries. The home state GDP of large nurseries was significantly larger than the home state GDP of small nurseries. The destination state GDP of large nurseries was not significantly different from that of small nurseries. Over $40 \%$ of the observations were from the South, and the rest of them were evenly distributed across the Northeast, Midwest, and West regions. The average age for small nurseries was 22 years in business and the average age for large nurseries was 34 years in business. The median age for small nurseries was 18 years and the median age for large nurseries was 27 years in business.

Eighty-seven percent of large nurseries primarily sold through wholesale channels and $60 \%$ of small nurseries mainly sold wholesale. Twenty-one percent of large nurseries exported some portion of their products outside the United States and $46 \%$ of large nurseries had production contracts. For small nurseries, only $7 \%$ exported and $29 \%$ had contracts. Among large nurseries, $22 \%$ mainly sold their product through negotiation and $94 \%$ sold their product to repeat customers. Among small nurseries, $17 \%$ primarily sold their product through negotiations and $78 \%$ sold their products to repeat customers.

Trees/shrubs were the major products for most nurseries. For both large and small nurseries, more than $55 \%$ had trees/shrubs as their major products. Among small nurseries, $9 \%$ had vines/groundcover as their major products, $14 \%$ had bedding plants as their major products, and $4 \%$ had foliage as their major products. Among large nurseries, 8\% had vines/groundcover as their major products, $13 \%$ had bedding plants as their major products, and $8 \%$ had foliage as their major products. $T$ test was used to compare the difference in the dependent and independent variables between large nurseries and small nurseries (as shown in the last column in Table 1). Most of these variables were significantly different at a 5\% level between the two groups.

We used OLS regression to estimate the gravity models. The Hausman test was performed for two sets of gravity model coefficients for large nurseries and small nurseries. The $P$ value of the Hausman test was $<0.001$. Therefore, we rejected the null hypothesis that the coefficients of the two models were the same and used two separate gravity models to explore how different factors affect the trade for large nurseries and small nurseries differently. Table 2 presents the results of these two gravity models. Wald tests were used to test the difference in the coefficients of the models for large nurseries and small nurseries. The last column in Table 2 gives the $P$ values of Wald tests. In the following section, we summarize the regression results of the gravity models and compare the results between small nurseries and large nurseries.

From the estimation results, as shown in Table 2, it was evident that the trade value of nurseries decreased as the distance between the home state and destination state increased. For small nurseries, the coefficient of distance was -1.038 , which indicates that a $1 \%$ increase in the distance between the home state and destination state caused $\mathrm{a} \approx 1 \%$ decrease in the trade value. For large nurseries, the coefficient of distance was -0.674 , which indicates that a $1 \%$ increase in the distance between the home state and destination state only led to $\mathrm{a} \approx 0.7 \%$ decrease in the trade value. The $P$ value of the Wald test for the difference between the coefficients of distance for large and small nurseries was $<0.001$, which indicates the impact of distance on large nurseries was significantly smaller than that on small nurseries.

Home state GDP and destination state GDP affected the trade value as well, and they affected large and small nurseries differently. For small nurseries, the coefficients of both home state GDP and destination state GDP were positive and significant. For small nurseries, a $1 \%$ increase in home state GDP was associated with $\mathrm{a} \approx 0.06 \%$ increase in the trade value, whereas a $1 \%$ increase in destination state GDP was associated with $\mathrm{a} \approx 0.31 \%$ increase in the trade value. For large nurseries, the coefficient of home state GDP was not significant and the coefficient of destination state GDP was positive and significant. A $1 \%$ increase in destination state GDP was associated with a $\approx 0.49 \%$ increase in the trade value for large nurseries. Buyers in a state with higher GDP would generally have a higher degree of purchasing power. For both large and small nurseries, the destination state GDP's effect on trade was larger than the home state GDP's effect on trade. The destination state GDP's effect on the trade value was smaller for small nurseries than that for large nurseries. These results indicate that trade is more sensitive to the GDP of destination states than that of the home state.

As expected, the impact of distance on the trade value changed over time. For both large and small nurseries, the coefficients of both $y 2008 * \ln \_$distance and $y 2003 * \ln \_$distance were positive and significant. This indicates that distance had less impact on the trade value in 2008 and 2003 than it did in 1998. 
Table 2. Results from the augmented gravity model used to analyze interregional nursery crop trade among U.S. states.

\begin{tabular}{|c|c|c|c|c|c|}
\hline & \multicolumn{2}{|c|}{ Small $(n=6877)$} & \multicolumn{2}{|c|}{ Large $(n=5666)$} & \multirow{2}{*}{$\begin{array}{c}\text { Wald Test } \\
P\end{array}$} \\
\hline & Coefficient & SE & Coefficient & SE & \\
\hline Ln_distance & $-1.038 * * *$ & 0.022 & $-0.674 * * *$ & 0.026 & 0.000 \\
\hline Ln_hgdp & $0.056 * * *$ & 0.020 & -0.030 & 0.025 & 0.023 \\
\hline Ln_dgdp & $0.305 * * *$ & 0.021 & $0.494 * * *$ & 0.024 & 0.000 \\
\hline \multicolumn{6}{|l|}{ Distance over time } \\
\hline Y2008*ln_distanc & $0.138 * * *$ & 0.008 & $0.027 * * *$ & 0.009 & 0.000 \\
\hline Y2003*ln_distance & $0.113 * * *$ & 0.008 & $0.038 * * *$ & 0.009 & 0.000 \\
\hline \multicolumn{6}{|l|}{ Distance and region } \\
\hline Northeast*ln_distance & $-0.122 * * *$ & 0.009 & $-0.102 * * *$ & 0.012 & 0.205 \\
\hline MidWest*In_distance & $0.053 * * *$ & 0.009 & $0.027 * *$ & 0.012 & 0.099 \\
\hline West*In_distance & $0.060 * * *$ & 0.009 & $0.096 * * *$ & 0.010 & 0.007 \\
\hline \multicolumn{6}{|l|}{ Other variable } \\
\hline Dold & $0.083 * *$ & 0.038 & $0.272 * * *$ & 0.039 & 0.001 \\
\hline Wholesale & $0.114 * * *$ & 0.038 & $-0.176^{* * *}$ & 0.061 & 0.000 \\
\hline Export & 0.064 & 0.064 & $0.088 *$ & 0.051 & 0.777 \\
\hline Contract & 0.008 & 0.036 & $0.086 * *$ & 0.041 & 0.160 \\
\hline Negotiation & -0.050 & 0.044 & $0.284 * * *$ & 0.047 & 0.000 \\
\hline Repeat & $0.134 * * *$ & 0.042 & 0.099 & 0.082 & 0.715 \\
\hline Trees/shrubs & 0.028 & 0.046 & -0.054 & 0.060 & 0.282 \\
\hline Vines/groundcovers & $-0.209 * * *$ & 0.066 & $0.219 * *$ & 0.086 & 0.000 \\
\hline Bedding plants & $0.231 * * *$ & 0.060 & $0.228 * * *$ & 0.075 & 0.976 \\
\hline Foliage & $0.413 * * *$ & 0.087 & -0.122 & 0.087 & 0.000 \\
\hline Intercept & $3.936 * * *$ & 0.254 & $3.310 * * *$ & 0.367 & - \\
\hline Adjusted $R^{2}$ & 0.289 & & 0.181 & & \\
\hline $\mathrm{AIC}$ & 23270 & & 20196 & & \\
\hline $\mathrm{BIC}$ & 23400 & & 20322 & & \\
\hline
\end{tabular}

*Significant at $10 \%$ level; **significant at $5 \%$ level; and ***significant at the $1 \%$ level. $\mathrm{AIC}=$ Akaike's Information Criterion; BIC = Bayesian's Information Criterion.

The $P$ values of Wald tests for the difference between the coefficients of both $y 2008 * \ln \_$distance and $y 2003 *$ ln_distance for large and small nurseries was $<0.001$, which indicates the impact the change of distance had on the trade value over time on large nurseries was significantly lower than that on small nurseries. For small nurseries, a $1 \%$ increase in distance was associated with a $0.90 \%(-1.038+0.138)$ decrease in the trade value in 2008 and a $1 \%$ increase in distance was associated with a $0.92 \%(-1.038+0.113)$ decrease in the trade value in 2003. The impact of the change of distance in 2008 was significantly higher than that in $2003(P<0.001)$ for small nurseries. For large nurseries, a 1\% increase in distance was associated with a $0.65 \%(-0.674+0.027)$ decrease in the trade value in 2008 and a $1 \%$ increase in distance was associated with a $0.64 \%(-0.674+0.038)$ decrease in the trade value in 2003 . The impact of the change of distance in 2008 was not significantly different from that in $2003(P=0.215)$ for large nurseries. Intuitively, the effect of distance on trade should be declining over time. With the development of transportation and storage technologies, it becomes easier to ship products farther away from the home state. Brun et al. (2005) used the gravity model to study the distance effect between 1962 and 1996. They found that high-income countries have gained more from the decreasing effect of distance on trade compared with low-income countries. Our study of national nursery trade showed that distance had a larger effect on trade value for small nurseries than for large nurseries. However, small nurseries benefit more from transportation and technology development over time than larger nurseries. The difference in the impact of distance on the trade value between large and small nurseries was diminishing. However, over time, the impact of distance on the trade value was still higher for small nurseries $(-0.90$ to -0.92$)$ than that for large nurseries $(-0.67$ to -0.68$)$.

The impact of distance in the trade value differed across regions as well. Compared with nurseries located in the South, the impact of distance on trade in the Northeast was larger, whereas the impact of distance on the trade in the Midwest and West was smaller. For small nurseries, a $1 \%$ increase in distance was associated with a $1.16 \%(-1.038-0.122)$ decrease in the trade value in the Northeast; a $1 \%$ increase in distance was associated with a $0.99 \%(-1.038+0.053)$ decrease in the trade value in the Midwest; and a 1\% increase in distance was associated with a $0.98 \%$ $(-1.038+0.060)$ decrease in the trade value in the West. For large nurseries, a $1 \%$ increase in distance was associated with a $0.78 \%$ $(-0.674-0.102)$ decrease in the trade value in the Northeast; a $1 \%$ increase in distance was associated with a $0.65 \%(-0.674+0.027)$ decrease in the trade value in the Midwest; and a $1 \%$ increase in distance was associated with a $0.58 \%(-0.674+0.096)$ decrease in the trade value in the West. For both large and small nurseries, distance had the largest effect on trade in the Northeast and distance had the smallest effect on trade in the West, where nursery firms are more accustomed to having to ship their products greater distances. For all regions, the impact of distance on the trade value was still higher for small nurseries $(-0.98$ to -1.16$)$ than that for large nurseries $(-0.58$ to -0.78$)$.

Several dummy variables related to business characteristics also had significant effects on the trade value. The number of years in business had a significantly larger effect on the trade value for large nurseries than for small nurseries. As expected, older nurseries had a higher trade value than younger nurseries. The more established the firm, the larger the gross sales. The trade value of older small nurseries (which stayed in business for more than 27 years) was $9 \%[\exp (0.083)-1]$ higher than that of younger small nurseries (which stayed in business for less than 27 years) and the trade value of older large nurseries was $31 \%[\exp (0.272)-1]$ higher than that of younger large nurseries.

For small nurseries, the trade value of these nurseries mainly producing for the wholesale market channel was $\approx 12 \% \operatorname{pexp}(0.114)-1]$ higher than that of nurseries mainly making retail sales. In contrast, for large nurseries, the trade value of nurseries primarily selling wholesale products was $\approx 16 \%[\exp (-0.176)-1]$ lower than that of these nurseries mainly making retail sales. Compared with small nurseries, more large nurseries primarily sold wholesale. However, among small nurseries, those who primarily sold through wholesale channels had a higher trade value. In contrast, among large nurseries, those who mainly sold through retail had a higher trade value. Retail selling requires more resources and expenses such as planting and selling simultaneously, the cost of owning or renting merchandising space, and higher labor costs. The trade value of large nurseries who exported products was $\approx 9 \%$ $[\exp (0.088)-1]$ higher than that of those who did not export. Compared with small nurseries, more large nurseries exported more nursery products and had production contracts. Large nurseries typically have more resources and financial capacity to work with foreign businesses. The trade value of large nurseries who had contracts was $\approx 9 \%[\exp (0.086)-1]$ higher than that of those who did not have contracts. In many such cases, contract sales are made before products are even planted. However, in the nursery industry, contract sales have risks for both buyers and sellers because contracts commonly are verbal rather than written (Navaja, 2003). Large nurseries are less likely to default on contracts, so contracts with large nurseries are more desirable to buyers. Negotiation is an important trade process with buyers and sellers coming together and discussing price, quantity, and other terms of sale. Negotiations take time and increase transactions costs, but they may increase the success of the trade. Compared with small nurseries, more large nurseries sold primarily through negotiations. Our study showed that large nurseries who mainly sold their products through negotiations had higher trade value. The trade value of large nurseries who mainly sold their products through negotiations was $\approx 33 \%$ [exp $(0.284)-1]$ higher than that of these who did not use negotiations as their primary means of selling their products. The trade value for small nurseries, who mainly 
sold their products to repeat customers, was $\approx 14 \%$ [exp $(0.134)-1]$ higher than that of those who did not primarily sell their products to repeat customers.

Our study also showed that nurseries with different major products had different levels of trade value. For small nurseries, who mainly sold vines/groundcovers, their trade value was $\approx 19 \%$ lower than that of nurseries who mainly sold other products. In contrast, for large nurseries, the trade value of nurseries who primarily sold vines/groundcovers was $\approx 25 \%$ higher than that of those nurseries who mainly sold other products. For both large and small nurseries, the trade value of nurseries who mainly sold bedding plants was $\approx 26 \%$ higher than that of those nurseries who mainly sold other products. The trade value of small nurseries who mainly sold foliage was $\approx 51 \%$ higher than that of nurseries who mainly sold other products.

\section{Conclusions}

This study uses gravity models and provides econometric evidence about how distance, market size, and characteristics of nurseries affect the interregional trade of nursery crops in the United States. We extended the standard gravity model by including interaction terms of distance with time and distance with region and some business characteristics. The augmented gravity models provide some evidence to support our main hypothesis that national nursery trade is impacted by distance, state GDP, size, and business characteristics. We were able to compare the difference between large and small nurseries by conducting the Wald tests. Similarity and difference exist between large nurseries and small nurseries.

Results of this study have important marketing implications for the nursery industry. The packing, storage, and shipping techniques for the nursery have been improved over time. With these technical developments, it is becoming easier to ship nursery crops over longer distances. As expected, we found that the impact of distance on trade is decreasing over time, which indicates that nurseries have more potential to consider developing new markets in states that are further away. However, we found that distance still has a relatively larger impact on the trade of nursery crops compared with many other agricultural products. For example, a $1 \%$ increase in the distance caused a $0.22 \%$ to $0.34 \%$ decrease in the trade value of meat (Koo et al., 1994). Nursery crops are different from many other agricultural products. Nursery crops are alive and it is relatively more time- and effortconsuming to move living plant materials around. The proper care of living plants is extremely important during shipping processes. Growing condition is another factor that restricts some nursery crops to be sold only to close regions. This is because some nursery plants may only be suitable to grow in certain climate environments. Previous studies have shown firm size and firm growth are often negatively correlated (Evans, 1987). Small nurseries are more likely in their growth stage, whereas large nurseries are more likely in their mature stage. Therefore, small nurseries might have greater potential to expand their markets. Business characteristics may affect the trade flow. For example, to increase the trade value, small nurseries should target the wholesale market channel, whereas large nurseries should target retail channels.

There are some limitations in this study. Approximately one-third of the observations in the data set was not included in the analysis as a result of missing values. Fortunately, the data set is large enough for us conduct a robust analysis. The value of distance was approximated, which might generate some bias in our results. Further studies with more accurate distance information can be used to validate our findings.

\section{Literature Cited}

Anderson, J.E. 1979. A theoretical foundation for the gravity equation. Amer. Econ. Rev. 69:106-116.

Anderson, L.E. and E. van Wincoop. 2004. Trade cost. J. Econ. Lit. XLII:691-751.

Baier, S.L. and J.H. Bergstrand. 2001. The growth of world trade: Tariffs, transport costs, and income similarity. J. Intl. Econ. 53:1-27.

Behe, B.K., J.H. Dennis, C.R. Hall, A.W. Hodges, and R.G. Brumfield. 2008. Regional marketing practices in U.S. nursery production. HortScience 43:2070-2075.

Bikker, J.A. 1987. An international trade flow model with substitution: An extension of the gravity model. Kyklos 40:315-337.

Bougheas, S., P.O. Demetriades, and E.L.W Morgenroth. 1999. Infrastructure, transport costs and trade. J. Intl. Econ. 47:169-189.

Brooker, J., D. Eastwood, C. Hall, K. Morris, A. Hodges, and J. Haydu. 2005. Trade flows and marketing practices within the United States nursery industry: 2003. Tennessee Agricultural Experiment Station. Southern Cooperative Bulletin 404.

Brun, J.F., C. Carrere, P. Guillaumont, and J. de Melo. 2005. Has distance died? Evidence from a panel gravity model. World Bank Econ. Rev. 19:99-120.

Bureau of Economic Analysis. 2010. 11 Oct. 2010. <http://www.bea.gov/regional/gsp/>.

Carrillo, C. and C.A. Li. 2002. Trade blocks and the gravity model: Evidence from Latin American countries. Discussion Papers, University of Essex, Essex, UK.

Deardorff, A.V. 1998. Determinants of bilateral trade: Does gravity work in a neoclassical world? In: Frankel, J.A. (ed.). The regionalization of the world economy. University of Chicago Press, Chicago, IL.

Egger, P. 2002. An econometric view on the estimation of gravity models and the calculation of trade potentials. World Econ. 25(2):297-312.

ERS/USDA. 2007. Floriculture and nursery crops yearbook. 11 Oct. 2010. <http://www.ers.usda. gov/publications/flo/2007/09Sep/FLO2007.pdfs.

Evans, D.S. 1987. The relationship between firm growth, size, and age: Estimates for 100 manufacturing industries. J. Ind. Econ. 35:567-581.
Frankel, J. 1997. Regional trading blocs in the world economic system. Institute for International Economics, Washington, DC.

Grant, J.H. and D.M. Lambert. 2008. Do regional trade agreements increase members' agricultural trade? Amer. J. Agr. Econ. 90: 765-782.

Hall, C.R., A.W. Hodges, and M.A. Palma. 2011. Sales, trade flows, and marketing practices within the U.S. nursery industry. Journal of Environmental Horticulture 29:14-24.

Hinson, R.A., S.C. Turner, and J.R. Brooker. 1995. Transactions methods among US wholesale nurseries. Agribusiness 11:147-154.

Hitomi, K., Y. Okuyama, and G.J.D. Hewings. 2000. The role of interregional trade in generating change in the interregional Leontief inverse in Japan, 1980-1990. Econ. Syst. Res. 12:515-537.

Hodges, A., C. Hall, B. Behe, and J. Dennis. 2008. Regional analysis of production practices and technology use in the U.S. nursery industry. HortScience 43:1807-1812.

Inmaculanda, M.-Z. and N.-L. Felicitas. 2003. Augmented gravity model: An empirical application to Mercosur-European union trade flows. Journal of Applied Economics 6:291-316.

Koo, W.W. and D. Karemera. 1991. Determinants of world wheat trade flows and policy analysis. Canadian Journal of Agricultural Economics $39: 439-445$

Koo, W.W., D. Karemera, and R. Taylor. 1994. A gravity model analysis of meat trade policies. Agr. Econ. 10:81-88.

Leamer, E. and J. Levinsohn. 1995. International trade: The evidence. In: Grossman, G.M. and K. Rogoff (eds.). Handbook of international economics. Vol. 3. Elsevier, North-Holland, New York, NY.

Linnemann, H. 1966. An econometric study of international trade flows. North-Holland Pub, Co., Amsterdam, The Netherlands.

Llano, C., A. Esteban, J. Perez, and A. Pulido. 2010. Opening the interregional trade "black box": The C-intereg database for the Spanish economy. Intl. Reg. Sci. Rev. 33:302-337.

Munroe, D. and G. Hewings. 1998. The role of intraindustry trade in interregional trade in the Midwest of the US. Discussion Paper. REAL. University of Illinois, Urbana-Champaign. In: Navaja, R.E. (ed.). 2003 Analyzing changes in contractual practices in the Louisiana nursery industry. MS thesis Louisiana State University .

Nijkamp, P., A. Reggiani, and W.F. Tsang. 2004. Comparative modelling of interregional transport flows: Applications to multimodal European freight transport. Eur. J. Oper. Res. 155: 584-602.

Pöyhönen, P. 1963. A tentative model for the flows of trade between countries. Weltwirtsch. Arch. 90:93-100.

Tinbergen, J. 1962. Shaping the world economy; suggestions for an international economic policy. Twentieth Century Fund, New York, NY.

Velástegui Andrade, M.A. and R.A. Hinson. 2009. Making the choice between rewholesalers and other nursery market channels. HortScience 44:372-376.

Zahniser, S.S., D. Pick, G. Pompelli, and M.J. Gehlhar. 2002. Regionalism in the Western hemisphere and its impact on U.S. agricultural exports: A gravity-model analysis. Amer. J. Agr. Econ. 84:791-797. 